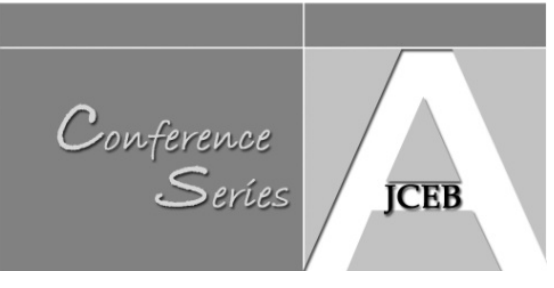

\title{
Disaster Restoration Projects: A Conceptual Project Management Perspective
}

Bassam Baroudi (University of South Australia, Australia)

Randy R. Rapp (Purdue University, United States of America)

\begin{abstract}
Disaster events create significant challenges for all those involved with affected people and communities having many needs in the ensuing period. One of the major needs is that of reinstating the built environment back to its original pre-disaster condition. That is the restoration and reconstruction of damaged structures. This paper particularly focuses in on the repair and mitigation aspect. These are termed disaster restoration projects and are thought to contain many unique problems not found within conventional construction. The area of project management is continually attracting interest from various sectors. This is mainly due to its perceived value within the business world. Hence, it seems worthwhile that the emerging disaster restoration field look to project management principles and knowledge for possible benefits. With this in mind this study initially presents some background in respect to disasters, restoration and project management. It then follows on to provide a commentary on the topic examining project organization, stakeholders, life cycles, processes and project management knowledge areas. The commentary is founded within project management best practice. Disaster restoration projects would appear to have their own unique attributes and problems. As such, examining disaster restoration projects through a project management lens provides an opportunity to enhance knowledge within this field. It is believed that the application of recognized project management concepts can lead to improved outcomes. This study should prove useful to those involved in disaster restoration projects across the developed and developing world.
\end{abstract}

Keywords: Disasters, restoration, project management

\section{Introduction}

The interest in disaster events appears to be steadfastly on the increase in recent years. Their widespread affects and frequency seem to be the stimulus for this interest. Many have noted that it does seem as if disaster occurrences are on the increase (Kitamoto, 2005; Whybark 2007; Bosher et al. 2009). This does indicate that disaster events are becoming a mounting problem for the developed and developing world. Hence, the number of studies into disaster management and related areas has experienced significant increases across a variety of disciplines. This study adopts a post disaster restoration perspective within the construction discipline that is fundamentally concerned with the repair and mitigation of damaged structures.

\section{Disaster Restoration Projects}

Disaster events have significant human and financial consequences for those living within affected regions. From the financial or commercial perspective many people and organisations are affected. Some of these include asset owners, businesses, government, insurance companies, construction and reinstatement organisations and charities. (Rotima et al., 2006). Furthermore, these stakeholders all tend to have some involvement in the recovery of the built environment post disaster. This physical recovery can be viewed as the sum of all restoration and reconstruction activities that bring affected structures back to their original condition (Rapp, 2010). However, it must be highlighted that there is a marked distinction between the "restoration" and "reconstruction" aspects. The restoration aspect 
seeks to repair existing structures to their pre-disaster state whilst the reconstruction aspect looks to essentially demolish and rebuild.

Disaster restoration projects can form a large part of the disaster recovery process. This has fostered an emerging and growing industry. Peacock et al. (2007) view building restorations as "restoration of the restorable". This situation sees buildings incurring limited damage and hence, not requiring demolition or complete rebuilding. Where restoration is not possible reconstruction activities need to take place. However, Alexander (2004) suggests that in the post disaster haste to rebuild, restorable buildings are often demolished to make way for newly constructed buildings. This would appear to be at the expense of time and cost. As Baradan (2006) points out, overall reconstruction periods can take between two and four years. Hence, restoration should always be assessed as a viable alternative to reconstruction. Notwithstanding, this would be dependent on the developed status of the region in question.

Both restoration and reconstruction projects require a certain way of thinking to foster successful outcomes. For disaster recovery to be effective Coles and Buckle (2004) suggest that the whole community must work in behind the effort. Aldrich (2012) puts forth that the social capital held within communities can make a big difference to post-disaster recovery. Moreover, Boeni and Jigyasuii (2005) contend that the cultural background of the affected region should demand significant attention. Another aspect to consider is that post disaster resourcing problems can exist due to supply lines being disrupted and general disorder within the construction marketplace (Chang et al., 2010). Furthermore, shortages of people with professional expertise and appropriate skills can create significant problems. The 2005 Sri Lanka Tsunami and the 2005 Northern Pakistan earthquake certainly displayed these signs (Hayles, 2010). The highlighted issues can produce challenges on a broad scale. Underdeveloped countries in particular struggle with restoring the built environment to its original condition.

Disaster restoration projects have their own unique considerations when remediating against events such as flood, fire or bad weather. Hence, an emerging restoration industry is developing to cater for this work. The industry has seen many organisations specifically set up for these projects with many others aligning their businesses to meet impending demand. In the end, demand and supply will decide the viability of these types of organisations. However, the peak industry body, the Restoration Industry Association (RIA), currently represents a membership of over 20,000 people (RIA, 2011) which suggests certain strength within this emerging field.

\section{Project Management Concepts}

Generic project management concepts are utilised within many diverse fields in the quest for successful organisational outcomes. Publications such as the Project Management Body of Knowledge - $\mathrm{PMBoK}^{\circledR}(\mathrm{PMI}, 2008)$ promote many of these concepts inclusive of project fundamentals, lifecycles, techniques, processes and various knowledge areas. The knowledge areas themselves provide an extensive management guide on scope, integration, time, cost, quality, human resources, communications, risk and procurement. There are many other systems that promote project management best practice but the founding principles are essentially similar.

Lock (1994, p3) sees project management as "achieving project goals with resources available". In addition, projects typically have scheduled commencement and completion times with single points of responsibility. Wright (1997) suggests that time and budgets are the twin imperatives that most clients subscribe to in projects. However it would seem that whilst traditional project management concepts hold reasonable value there is a movement towards placing greater emphasis on other areas such as soft skills, strategy and sustainability. For example, Pant and Baroudi (2008) argue that publications such as

Baroudi, B., and Rapp, R.R. (2012) 'Disaster restoration projects: A conceptual project management perspective', Australasian Journal of Construction Economics and Building, Conference Series, 1 (2) 72-79 
PMBoK $^{\circledR}$ tend to place too much emphasis on technical skills and not enough on soft skills. This is at a time when the topic of leadership is becoming quite prominent within project management forums. Desired leadership capabilities are expressed quite well by Bartol et al (2001). They see leaders in terms of being initiators, contributors, coordinators, energisers, encouragers and harmonisers. Within disaster restoration projects these broad concepts would seem useful.

Successful project outcomes essentially drive overall project success. Kerzner (2009) points out the definition of success within project management can quite simply be seen as the achievement of desired project objectives. In the context of disasters, Learnard and VanOrnum's (2011) reported that project management approaches can solve problems and provide successful outcomes via recognised structured methodologies. This was from testimony by the Project Management Institute to a US Senate panel which went further to show that research indicated that reconstruction efforts benefit from the leadership and clarity that project management delivers. The linking of success to project management use increasingly makes it an attractive proposition to a wide variety of industries and organisations.

Foti (2001) predicts that as managing-by-projects methodology becomes embedded in corporate culture, globally accepted standards will govern those who pursue project management careers. This increasingly appears to be the case via a variety of professional and industry body initiatives. The PMl's Project Management Professional (PMP) accreditation is a good example of this. Furthermore, a good example within the disaster restoration context comes from the Restoration Industry Association (RIA) currently publishing a Certified Restorer ${ }^{\circledR}$ Body of Knowledge (CRBoK) with its own particular emphasis on project management (Rapp and Baroudi, 2012). Initiatives such as these encourage the profession/workforce to become knowledgeable on project management concepts in either generic or specialised contexts.

In summary, it is believed that disaster restoration projects will benefit from adopting project management best practice. These projects require high levels of management capability involving resource availability, integration, and coordination to provide an orderly progression back to the built environments' original condition. It is thought that using important project management concepts as a lens over disaster restoration projects can provide useful information. Hence, the following commentary discusses disaster restoration projects in light of current project management knowledge.

\section{Disaster Restoration Project Management Commentary}

The aim of the following commentary is to discuss disaster restoration projects and examine how project management might benefit industry practices. It will provide considerations for the management of these projects and some novel insights into the disaster restoration field. The focus will be on project management concepts in respect to project organisation, stakeholders, life cycles, processes and knowledge areas. It is thought that discussing disaster restoration projects in light of these concepts will provide useful perspectives on this area and highlight how project management thinking can be applied.

\section{Project Organisation and Stakeholders}

Project organisations and organisations that manage projects are tasked with creating management structures that allow the achievement of goals in line with project objectives. In the field of post disaster restoration and reconstruction the challenge of restoring damaged property commences once the work of emergency service providers is complete. These contractors can come with various qualifications with the most obvious appearing to be construction, however, restoration based contractors in particular can come from many other backgrounds notably including cleaning, maintenance, and the fabric/garment area.

Baroudi, B., and Rapp, R.R. (2012) 'Disaster restoration projects: A conceptual project management perspective', Australasian Journal of Construction Economics and Building, Conference Series, 1 (2) 72-79 
The projects can involve repair and mitigation work to public buildings, private dwellings and possibly infrastructure.

Restoration firms need to be able staff their organisations with capable competent operatives who are ready to act on disaster remedial works as required. Disaster restoration projects can individually be small or large. These are designated to project managers that need to deliver on the project's scope and expectations. It would be prudent for restoration project managers to prepare a project plan that outlines the requirements of each project. It is also of some importance that these organisations consider high demand situations and therefore capacity needs to be built into their management structures to cope with busy times. This would most likely be via a network of subcontractors that can respond to emerging situations on an "as need" basis. As such, firms retain the flexibility to remain viable in lean times and the ability to absorb greater workloads during periods of high demand. In times of "CAT" or catastrophic disasters this may yet not be enough and restoration companies outside the affected regions may indeed play a large part in restoring the built environment. Moreover, in the case of underdeveloped countries restoration expertise may need to be drafted in. The controlled demolition or "tear-out" can be undertaken with relatively unskilled labour but the repair or "put-back" demands skilled labour. This can be in short supply when a large region is damaged. This is exacerbated when disasters strike the same general region in short succession such as did hurricanes Katrina, Rita, and Wilma between August and October 2005. Furthermore, work productivity and quality can ultimately suffer.

Restoration projects have many stakeholders that need consideration. Project stakeholders can be referred to as any person or organisation that is influenced or affected by a situation. An expanded list outside of the restoration contractors and staff themselves includes building owners and occupiers, emergency services, utilities providers, government bodies, businesses, insurers, mortgage companies, building consultants (including indoor environmental professionals), specialist subcontractors, charity groups, etc. These projects are seen as being quite unique in the various stakeholders that are assembled within them. The project manager as the single point of responsibility particularly needs to build strong stakeholder relationships whilst delivering successful outcomes. A further challenge is the aspect of stakeholder emotion and distress which should never be overlooked or disregarded within these types of projects.

Disaster restoration project organisations and their stakeholders create the processes that ultimately deliver disaster affected built environments back to normality. Hence, it is imperative that these organisations and people work within some form of structured methodology to deliver on projects. Bodies such as the Restoration Industry Association are seen to provide support within these areas with the publishing of the aforementioned Certified Restorer ${ }^{\circledR}$ Body of Knowledge being just one example.

\section{Project Lifecycle and Processes}

Projects are quite often viewed as having four phases. These phases are based within the areas of initiation, planning, execution and closure. Projects by their very nature involve the interaction of many related processes and activities. It is these items that come together to form the project lifecycle. The project lifecycle therefore houses all the necessary operations to deliver the project to completion. Each project process will have its own duration and needs to be scheduled into timeline that achieves the project objectives as prescribed by the project plan.

Disaster restoration projects require in the first instance the initiation of the necessary processes to commence work. A priority is the appointment of the project manager to lead the project team. Also at the initiation stage all projects need to determine their source of funding. The disaster restoration industry is seen to have the insurance sector as one of its major drivers within the area of funding. Hence, claims approvals must be forthcoming so

Baroudi, B., and Rapp, R.R. (2012) 'Disaster restoration projects: A conceptual project management perspective', Australasian Journal of Construction Economics and Building, Conference Series, 1 (2) 72-79 
that funds can flow to finance the restoration works. It appears that all too often this is not the case. The recent case with the Queensland Floods of 2011 lies as evidence to this. Once, the initial project determinations alongside the scoping of the extent of work have been made then the more detailed planning phase can commence.

The planning phase of a project sets out the "how, what, when and where" in respect to the processes and activities that need to be accomplished. As far as restoration projects assessments will need to be made on what can be restored and what can't. This phase may therefore include commissioning any consultants and design work as may be needed to report on the situation and offer advice. In many instances the restoration contractor may be the consultant and contractor in one as they are specialist within the field. Properly trained and certified restoration professionals can perform "triage" to determine which structures and property can be repaired and those which should be demolished. From here any documentation, regulatory approvals and pricing will need to be carried out so that the project plans can move into the execution stage which is where the physical project deliverables are essentially realised.

The execution phase is seen as the time at which the works commence on the restoration site. In disaster restoration projects this can sometimes be challenging due to problems of access or services availability. This is due to the nature of a disaster scene or region which is still reeling from the effects of events such as fire, hurricane, flooding, etc. The project team needs to asses this situation to ensure timely commencement on the restoration works. After all, there could be a family that has been left without a place to live or a business without premises to operate from. So in the broader sense the disaster restoration project team is restoring social and business continuity as best and as quickly as they possibly can. As such, they need to manage, monitor and control activities against documented baselines. However, restoration activities can present latent problems that may not be as foreseeable as in reconstruction or new works. Immediately following the execution phase marks the commencement of project closure activities. This basically involves the finalisation of all disaster restoration processes and activities. This would include aspects such as undertaking final inspections, reconciling accounts and accommodating any building owner and/or insurer concerns. Also, documenting project outcomes and promoting lessons learned would illustrate good project management practice.

The lifecycle and phases associated with disaster restoration projects are quite dependent on the type and scale of the disaster event. Of notable importance and relevance is the region where the disaster occurs. The level of economic and social development can significantly impact on the recovery lifecycle as a whole. This is said with underdeveloped countries in mind.

\section{Project Management Knowledge Areas}

As previously indicated the Project Management Body of Knowledge - PMBoK ${ }^{\circledR}(\mathrm{PMI}, 2008)$ covers many project management aspects including nine knowledge areas: scope, integration, time, cost, quality, human resources, communications, risk and procurement. The following will use these project management knowledge areas to specifically analyse and discuss disaster restoration projects.

Disaster restoration projects need to establish the project scope as a first point of order. This in effect will determine whether the project falls into either the disaster "restoration" or disaster "reconstruction" category. If it is a reconstruction project then it is basically a demolish and rebuild. However, if it is a restoration project it is more a repair and mitigate type of exercise. Therefore from a disaster restoration standpoint this means that a scoping exercise should be undertaken in respect to the required remedial works. As such a scoping document should be produced indicating what is included in the project but also importantly, what is excluded. The integration aspect within project management is

Baroudi, B., and Rapp, R.R. (2012) 'Disaster restoration projects: A conceptual project management perspective', Australasian Journal of Construction Economics and Building, Conference Series, 1 (2) $72-79$ 
essentially the bringing together and coordinating of all the various activities. Within restoration projects this would include technical staff, specialist contractors and many other stakeholders.

The concepts of time, cost and quality are often raised as the triangle of core objectives for project success. As earlier indicated, highlighting these types of concepts is a fairly traditional view as today the profession is more informed to recognise other broader success criteria in areas such as leadership and sustainability. However, it is suggested that these three objectives are still always at the fore. Disaster restoration project management has its own unique aspects in respect to these objectives. For example, time management can become an issue if there is a delay with building or insurance claim approvals. This is particularly exacerbated when a disaster affects a wide region and regulating authorities and insurance companies are overwhelmed with submissions and claims. In these cases extended timelines can lead to social breakdown in families and communities and prolong business losses. Hence it is important for restoration contractors to commence as soon as possible and maintain tight schedules. Also, from the restorer's perspective they need to start work as this impinges on their livelihoods. This follows onto cost management which also creates issues within restoration works. The very nature of repairing existing structures and buildings can be difficult to price notwithstanding the discovery of latent conditions post commencement. As such, this type of work might commonly see cost/budget overruns not experienced with newer work. The aspect of quality can be serviced well by appropriate quality assurance systems. However, within restoration projects problems such as mould growth (after flooding) as well as ineffective odour removal (after fire) may present further issues for building occupiers. Hence, rigorous control procedures need to be adopted by restoration contractors to avoid future liability.

It was previously raised that one of the most topical subjects in project management today is the concept of leadership. Or better still effective leadership. Leadership concepts sit within the knowledge area of human resources management. The quality of project leaders, and indeed the project teams they lead, is the same to restoration projects as it is to other project types. However, what makes restoration projects unique is dealing with disaster affected people and working amongst disaster affected areas. Project leaders need to be astute business professionals but they also need to display softer social skills such as compassion and integrity to win over stakeholders and to effectively manage their team. Furthermore, effective project communications management is vital for successful outcomes. This can be in the use of well-honed interpersonal skills when dealing with people to the use of hard documentation outlining information such as project plans, reports, schedules and budgets.

Disaster restoration projects undoubtedly carry significant risk and it could be argued that they possibly harbour greater risk than conventional construction projects. Hence, project risk management is critical within disaster restoration work to determine the risk environment. This involves identification, assessment, mitigation and control of possible uncertainties within disaster restoration projects. Risks within disaster restoration projects could be found in the areas such as: worker safety, unanticipated works, regulatory hurdles, workforce availability, and repeat disaster occurrences. So risk management is essentially concerned with avoiding or managing unwanted situations. Project procurement on the other hand seeks to reduce risk by transferring it to third parties. It is principally concerned with the external sourcing of all goods and services for a project. Disasters restoration projects like all projects need adequate supply lines. The unique aspect with restoration projects is that they are unplanned events so sourcing all requirements at short notice can produce challenges. Furthermore, CAT events produce an environment where demand can exceed supply so the sourcing of labour and materials for restoration activities could be hampered. Even with assistance from unaffected regions or countries the time implications

Baroudi, B., and Rapp, R.R. (2012) 'Disaster restoration projects: A conceptual project management perspective', Australasian Journal of Construction Economics and Building, Conference Series, 1 (2) 72-79 
could be significant. The cost ramifications could also be problematic. These issues would be particularly detrimental to underdeveloped countries.

The above discussion provides only a brief insight into some issues involved in disaster restoration projects as viewed via a series of project management knowledge areas. However, it does provide a way of thinking about these problems by framing the arguments within recognised project management concepts. While sharing many concerns, skills and knowledge, project management for disaster restoration is not quite the same as that for conventional construction projects. Understanding the differences makes for a better chance of success.

\section{Conclusion}

This paper has set out to provide a conceptual project management perspective on disaster restoration projects. It provided a review of literature relevant to disaster restoration projects as well as a brief overview on basic project management principles and thinking. It then used concepts within project organisation, stakeholders, lifecycles, processes and knowledge area as a lens to view disaster restoration projects. Moreover, it importantly confirmed restoration as a repair and mitigation activity as distinct to reconstruction being a demolition and rebuilding activity.

The use of project management knowledge such as that contained within the $\mathrm{PMBoK}^{\circledR}$ allowed the study to investigate various areas within the disaster restoration industry, element by element. It already provides many industries with a framework to achieve desired goals within complex/challenging situations. As such, the study sought to apply proven and recognised generic project management knowledge and methodologies to disaster restoration situations. The intention of the discussions was to highlight unique perspectives in respect to project management concepts as applied to disaster restoration projects and help to fill the knowledge gap within this area.

Natural and manmade disasters would appear to be on the increase in both developed and underdeveloped countries. Disaster restoration, as opposed to total reconstruction, already saves billions of dollars each year throughout the world. It is thought that knowledge derived from studies such as this one might significantly enhance management practices and possibly improve efficiencies and thus increase savings. This study is part of other research that is occurring on an international basis. The continuing research seeks to deliver valuable "application ready" project management knowledge tailored for the disaster restoration industry.

\section{References}

Aldrich D. P. 2012, Building Resilience: Social Capital in Post-Disaster Recovery, University of Chicago Press.

Alexander, D. 2004. Planning for post-disaster reconstruction, $2^{\text {nd }}$ International Conference on PostDisaster Reconstruction: Planning for Reconstruction, I-Rec 2004, Coventry, UK.

Baradan, B. 2006, Analysis of the Post-disaster Reconstruction Process following Turkish Earthquakes, 1999, $3^{\text {rd }}$ International Conference on Post-Disaster Reconstruction: Meeting Stakeholder Interests, I-Rec, Florence, Italy, 17-18 May, 2006.

Bartol, K., Martin, D., Tein, M., Matthews, G. 2001, Management, A Pacific Rim Focus, 3rd Edition, McGraw Hill.

Boeni, T., Jigyasuii, R. 2005, Cultural Considerations for Post Disaster Reconstruction Post-Tsunami Challenges, UNDP Conference.

Baroudi, B., and Rapp, R.R. (2012) 'Disaster restoration projects: A conceptual project management perspective', Australasian Journal of Construction Economics and Building, Conference Series, 1 (2) 72-79 
Bosher, L., Dainty, A., Carrillo, P., Glass, J. and Price, A. 2009, Attaining improved resilience to floods: a proactive multi-stakeholder approach, Disaster Prevention and Management, Vol. 18, No. 1, pp. 9-22.

Carey Learnard, C., VanOrnum, R. 2011, Project Management Institute Testifies on Disaster Relief Project Management, 20th October 2011, Project Management Institute (PMI): http://www.pmi.org/en/About-Us/Press-Releases/Project-Management-Institute-Testifies-onDisaster-Relief-Project-Management.aspx (Accessed August 2012)

Chang, Y., Wilkinson, S., Potangaroa, R. and Seville, E. 2010, Resourcing challenges for postdisaster housing reconstruction: a comparative analysis, Building Research \& Information, Vol. 38, No. 3, pp., 247-264

Coles, E. and Buckle, P. 2004, Developing community resilience as a foundation for effective disaster recovery, The Australian Journal of Emergency Management, Vol. 19, No. 4, pp. 6-15.

Foti, R. 2001, Forecasting the future of project management, PM Network, October issue, pp. 29-31.

Hayles, C., S. 2010, An examination of decision making in post disaster housing reconstruction, International Journal of Disaster Resilience in the Built Environment, Vol. 1 No. 1, pp. 103-122.

Kerzner, H. 2009, Project Management: A Systems Approach to Planning, Scheduling, and Controlling, John Wiley \& Sons, New Jersey.

Kitamoto, M. 2005, Total disaster risk management: good practices, Asian Disaster Reduction Center, Kobe, Japan.

Lock, D.1994, Gower Handbook of Project Management, Second Edition, Gower Press.

Project Management Institute, 2008, Project Management Body of Knowledge Guide (PMBoK ${ }^{\circledR}$ Guide), 4th Edition, Pennsylvania.

Rapp, R. R. 2011, Disaster recovery project management: Bringing order from chaos, Purdue University Press, West Lafayette, Indiana.

Restoration Industry Association (RIA). 2012, About RIA, Available at: http://www.restorationindustry.org (Accessed June 2012)

Rotimi, J. O. B., Le Masurier, J. and Wilkinson, S. 2006, The regulatory framework for effective post disaster reconstruction in New Zealand, $3^{\text {rd }}$ International Conference on Post-Disaster Reconstruction: Meeting Stakeholder Interests, I-Rec, 2006, Florence, Italy.

Pant, I., Baroudi, B. 2008, Project Management Education: The Human Skills Imperative, The International Journal of Project Management, Vol. 26, No. 2, 2008, pp 124-128.

Peacock, W.G., Dash, N., Zhang Y. 2007, Sheltering and Housing Recovery Following Disaster, Handbook of Disaster Research, Editors: Rodriguez, H., Quarantelli, E. L., Dynes, R. R., Springer, New York.

Whybark, D. C. 2007, Issues in managing disaster relief inventories, International Journal of Production Economics, Vol. 108, No.s 1-2, pp. 228-235.

Wright, J. N. 1997, Time and Budget - The Twin Imperatives of a Project Sponsor, International Journal of Project Management, Vol. 15, No. 3, pp. 181-186.

Baroudi, B., and Rapp, R.R. (2012) 'Disaster restoration projects: A conceptual project management perspective', Australasian Journal of Construction Economics and Building, Conference Series, 1 (2) 72-79 